Published in final edited form as:

Trends Cardiovasc Med. 2017 February ; 27(2): 136-140. doi:10.1016/j.tcm.2016.07.006.

\title{
Cardiovascular disease in patients with rheumatoid arthritis
}

\author{
Katherine P. Liao, MD, MPH \\ Division of Rheumatology, Immunology, and Allergy, Brigham and Women's Hospital
}

\begin{abstract}
The risk of cardiovascular disease (CVD) in patients with rheumatoid arthritis (RA) is $1.5-2$ fold higher than age- and sex- matched individuals from the general population. This excess risk is attributed to the systemic chronic inflammation which is a hallmark of RA. Challenges to optimizing $\mathrm{CV}$ risk management in RA include the need for improved methods to predict $\mathrm{CV}$ risk, and defining the target risk factor(s) to reduce $\mathrm{CV}$ risk. Lessons learned from RA studies can also inform CV risk prevention in the general population, where inflammation also has an important role in the pathogenesis of atherosclerosis.
\end{abstract}

\section{Keywords}

cardiovascular disease; rheumatoid arthritis; inflammation; lipids; lipoproteins

JS is a 34 year old woman who presented with "pain in the joints of her fingers, wrists, and knees. The first symptoms [included] pain, redness, swelling, and difficulty moving set in." This classic presentation of rheumatoid arthritis (RA) was written by Dr. Landre-Beauvais in 1800, where RA was identified for the first time as a distinct clinical entity[1]. The presentation of RA remains the same to this day. However, we now know that the inflammation of RA affects more than just the joints. Inflammation is considered the major contributor of the 1.5-2.0 fold excess CV risk in RA compared to the general population [25]. While overall the absolute rates of CVD are declining in the population, the relative risk of CVD in RA compared to the general population appears stable over the past 2 decades despite improvements in both RA and CVD management $[3,6,7]$. This review will survey a few of the challenges toward optimizing $\mathrm{CV}$ risk and the available evidence to address these issues.

\section{CALCULATING CV RISK IN RA}

In the general population, CVD is a preventable condition, with established methods for screening, and interventions that can prevent or mitigate the risk of disease. While these strategies appear to be utilized in RA patients in a similar manner as the general

Correspondence: Katherine P. Liao, MD, MPH, Division of Rheumatology, Immunology, and Allergy, Brigham and Women's Hospital, 75 Francis St, PBB-B3, Boston, MA 02115, kliao@partners.org, 617-732-5325.

Publisher's Disclaimer: This is a PDF file of an unedited manuscript that has been accepted for publication. As a service to our customers we are providing this early version of the manuscript. The manuscript will undergo copyediting, typesetting, and review of the resulting proof before it is published in its final citable form. Please note that during the production process errors may be discovered which could affect the content, and all legal disclaimers that apply to the journal pertain. 
population[8], RA patients continue to have excess $\mathrm{CV}$ risk. To improve $\mathrm{CV}$ outcomes in $\mathrm{RA}$, more studies are needed to identify and target $\mathrm{CV}$ risk factors which may be specific to RA patients. The lessons learned from studying RA may inform CV prevention in the general population where inflammation also plays an important role in $\mathrm{CV}$ risk. As an example, the Cardiovascular Inflammation Reduction Trial (CIRT) study[9] is randomizing patients without inflammatory diseases at high risk for myocardial infarction (MI) to the first-line RA treatment, methotrexate (MTX), or a placebo. CIRT builds on studies in RA demonstrating that treatment with MTX, which reduces inflammation, also reduced CV risk in RA patients[10].

One of the major challenges to understanding $\mathrm{CV}$ risk in RA is accurately defining the atrisk population. The excess $\mathrm{CV}$ risk in RA is attributed to inflammation; however, current methods to assess $\mathrm{CV}$ risk cannot account for long term exposure to inflammation. The Framingham Risk Score (FRS)[11] and SCORE[12] underestimate CV risk in RA by as much as 2-fold[13]. Similar findings were observed when the 2013 ACC/AHA CV risk assessment guidelines[14] were applied to an RA population[15]. The Reynolds Risk Score (RRS), which includes an inflammatory marker, high-sensitivity C-reactive protein (hsCRP), also underestimated CV risk in RA similar to FRS[13]. The most likely reason for this was because RRS was developed and validated in populations where the median hsCRP was $2.0 \mathrm{mg} / \mathrm{L}$ (IQR 0.8 to $4.3 \mathrm{mg} / \mathrm{L}$ ). In a typical RA cohort, the mean hsCRP was $9.7 \mathrm{mg} / \mathrm{L}$ (SD 0.66)[16], well above the hsCRP of $1.66 \mathrm{mg} / \mathrm{L}$ (SD 0.08) observed in the general population [17] (Figure 1). The QRISK2, the CV risk calculator used in the United Kingdom (UK), includes RA as a risk factor but was found to overestimate CV risk in one study[18]. The European League Against Rheumatism (EULAR) published recommendations for use of a 1.5 multiplier on FRS or SCORE for RA patients who have specific risk factors, such as positive rheumatoid factor (RF) or disease duration $>10$ years[19]. This strategy was based on expert opinion and has not undergone external validation.

Additionally, the use of carotid intima media thickness (cIMT) as a potential tool to better identify RA patients at high CV risk has been studied. A meta-analysis demonstrated increased cIMT in RA compared to controls[20], suggesting higher atherosclerotic burden. Higher levels of inflammation are associated also associated with increased cIMT[21]. However, only one study of 47 RA patients has been published demonstrating an association between cIMT and future $\mathrm{CV}$ events in RA[22]. Larger prospective studies are needed to examine the utility of cIMT integrated with clinical factors to assess CV risk. Presently, there are no widely accepted approaches for $\mathrm{CV}$ risk stratification for RA. Approaches that rely on traditional risk factors to estimate $\mathrm{CV}$ risk have led to misclassification largely toward underestimating risk. Thus, an important next step is to develop and validate a CV risk score tailored for RA patients by incorporating either more clinical factors or additional biomarkers.

In the general population, the adoption of FRS into the clinic was estimated to have cut CV deaths by 50\%[23]. The FRS was effective not only because it identified patients at elevated risk, but because it also identified risk factors that could be modified, e.g. cholesterol, to reduce this risk. Work is underway to develop a similar tool for RA which builds upon risk factors in FRS[24]. To date, there is one published study of a CV risk score developed in an 
RA population[25]. While this RA CV risk score still requires external validation, it provides a potential starting point for a clinical CV risk prediction tool. In this study, a baseline model was created using risk factors from the FRS including age, gender, diagnoses of diabetes, hyperlipidemia, hypertension and current tobacco use. RA clinical factors were then tested for their value in improving the accuracy of predicting a CV event. The final published model includes traditional risk factors plus the following RA clinical factors: RA clinical disease activity index (CDAI), functional status, corticosteroid use, and RA disease duration. Of the RA specific factors, the CDAI, functional status, and corticosteroid use were modifiable risk factors. The fact that CDAI was predictive for future $\mathrm{CV}$ risk raises an important question about the target for RA treatment- whether reducing CDAI would reduce CV risk. In the 2012 American College of Rheumatology (ACR) and the 2013 EULAR treatment guidelines for RA, the target for therapy is low disease activity (LDA) or remission. This target was selected based on studies demonstrating that LDA or remission can slow or halt the progression of joint damage[26]. Based on data that there is a linear relationship between lower disease activity and reduced $\mathrm{CV}$ risk, a more stringent target of remission for RA patients may not only mitigate joint damage, but also reduce CV risk [27, 28]. The Treatments Against RA and Effect on FDG PET-CT (The TARGET Trial), a randomized controlled multi-center study, is now enrolling to directly test the hypothesis that reducing inflammation reduces $\mathrm{CV}$ risk in RA[29]. A study demonstrating CV benefit in RA patients with tighter control of disease activity may lead to changes in the current approach to RA treatment towards tighter control of inflammation.

\section{LINKS BETWEEN INFLAMMATION AND INCREASED CV RISK}

Inflammation may modify traditional risk factors such as routine lipids, rendering them as suboptimal measures of future CV risk in RA. In a cross-sectional study, RA patients have a lower TC and LDL-C when compared to age- and sex- matched individuals from the general population[30]. These data appear contrary to the known excess $\mathrm{CV}$ risk observed among RA patients. Furthermore, data from RA treatment studies have found that potent disease modifying anti-rheumatic drugs (DMARDs), specifically the biologic DMARDs, are linked to changes in routine lipids. Routine lipids measurements performed from samples collected before and after tumor necrosis factor inhibitor (TNFi) from randomized controlled trials showed that TC and LDL-C levels increased by as much as 30\% after TNFi use[31]. Observational and retrospective studies of other biologic DMARDs, tocilizumab [32, 33] and tofacitinib[34] found similar trends with increases in TC and LDL-C, and heterogeneous changes in HDL-C. In a study examining the relationship between inflammation and lipids regardless of RA treatment, RA patients who experienced a reduction hsCRP $\geq 10 \mathrm{mg} / \mathrm{L}$ between two consecutive years also had increases LDL-C by $7.2 \%$ without significant changes in TC and HDL-C[35]. Overall, these data suggest that measuring routine lipids for $\mathrm{CV}$ risk assessment should be done when the patient is in low disease activity or remission. There is also emerging evidence to suggest that inflammation may modify traditional risk factors beyond lipids[21].

Direct measures of lipoprotein properties, such as lipoprotein composition and function, may improve $\mathrm{CV}$ risk assessment in the general population beyond consideration of routine lipid measures alone. Available studies suggest certain advanced lipoprotein tests, such as HDL 
cholesterol efflux capacity, may have a more consistent correlation with CV risk in RA than routine lipid levels; HDL cholesterol efflux capacity improves with reduction in inflammation[35, 36]. Whether these measurements will improve CV risk assessment in RA patients beyond measurements of routine lipids in the setting of a comprehensive risk calculator remains to be seen.

\section{Inflammation plays a central role in the pathogenesis of RA as well as atherosclerosis in the general population[37]}

We highlight here a few examples of inflammatory pathways, important in both RA and CVD, from blood biomarker studies in humans. Tocilizumab, an IL-6 receptor (IL-6R) anatagonist ${ }^{33}$, is an effective treatment for RA. This same inflammatory pathway was implicated as a causal pathway in coronary artery disease (CAD) in the general population[38]. Clinical trials are underway to determine whether patients at risk for CAD from the general population may benefit from tocilizumab[39]. Matrix metalloproteinases (MMPs) are associated with unstable plaque and rupture. Some subsets confer stabilizing effect on plaque while others have a destabilizing effect[40]. Patients with early RA have high levels of MMPs that in turn are associated with cartilage and bone destruction[41, 42]. A common genetic variant in CD40 is associated with risk of RA[43] and was functionally linked with upregulation of the CD40-CD40L pathway in RA[44-46]. Studies of this same pathway in CVD have found that levels of soluble CD40 ligand (sCD40L) are predictive of MI, and associated with plaque rupture and thrombosis[47, 48]. These shared inflammatory pathways between active RA and unstable plaque correlate with post-mortem findings in aortic plaques. Although RA patients appeared to have less plaque burden, they had a significantly higher percentage of unstable plaque compared to age- and sex-matched controls[49].

\section{Inflammation may lead to increased CV risk through pathways independent of atherosclerosis}

Endothelial dysfunction and microvascular disease are also hypothesized to play an important role in the development of CVD in RA[50, 51]. Measurements of coronary flow reserve (CFR) reflect coronary vasomotor function, and have been studied as a surrogate marker of $\mathrm{CV}$ risk. In patients with early RA, CFR was found to be significantly impaired compared to controls [52]. In RA with no known history of CVD, significant improvements in CFR (increase of $12.5 \%, \mathrm{p}=0.01$ ) were observed after a year of DMARD therapy, while no effect was observed on carotid intima media thickness ${ }^{17}$. Among RA patients with no history of CVD, patients with higher hsCRP and higher levels of RA disease activity had significantly higher high sensitivity cardiac troponin (hs-cTn) levels compared to those with lower hsCRP and RA disease activity[53], suggesting link between inflammation and subclinical myocardial injury. In summary, the evidence points to several potential mechanistic links between inflammation and CVD in RA through atherosclerosis and endothelial dysfunction. 


\section{RISK MANAGEMENT IN RA}

\section{Despite knowledge of elevated CV risk in RA, there are limited evidence regarding the best method to manage the excess risk[54]}

A large randomized controlled trial based in the UK (TRACE-RA) of 2986 RA patients randomized to atorvastatin 40mg QD or placebo regardless of LDL-C level for primary prevention of CVD yielded equivocal results[55]. While they observed a $34 \%$ reduction in $\mathrm{CV}$ risk for subjects on statins, the reduction was not statistically significant. Another proposed strategy to reduce $\mathrm{CV}$ risk in RA is to obtain tight control of inflammation through aggressive DMARD use[56]. Whether reduction in inflammation reduces the CV risk is being investigated in the TARGET study that is now enrolling[29].

Based on the evidence available today, CV management in RA patients remains an art of combining general population based guidelines with expert opinion[14, 54, 57]. At minimum, RA patients should be regularly evaluated for $\mathrm{CV}$ risk factors based on population guidelines for their age and gender. For lipid monitoring, patients should be either assessed when they are at low disease activity or in remission. Alternatively, patients who had lipids measurements performed when they were having active disease should have lipids rechecked when their RA disease activity has improved. Two RA treatments have package inserts recommending additional screening. For patients on tocilizumab, the manufacturer recommends checking cholesterol 4-8 weeks after initiation, and every 24 weeks thereafter. For tofacitinib, a JAK inhibitor, measurement of routine lipids is recommended 4-8 weeks after initiation; LDL-C levels are reported to maximize at 6 weeks. Statins are the first line therapy for lipid management in RA.

In summary, additional studies are needed to identify the RA specific risk factors that should be considered when calculating risk and the best method of measurement. Observational studies have demonstrated the importance of including a measurement for inflammation when assessing CV risk. However, the optimal method for measuring inflammation is not known. In most population based CV risk scores, baseline measures are entered into the calculation. In RA, inflammation changes over time with treatment and with flares. Thus, different methods of capturing the burden of inflammation will need to be considered. Assuming inflammation is the target, the next steps include determining first, the impact of reduction of inflammation on $\mathrm{CV}$ risk, and second, whether one treatment strategy for achieving control of inflammation would reduce $\mathrm{CV}$ risk more than others. As mentioned previously, there is evidence to suggest that targeting IL-6R may directly target the pathway for $\mathrm{CAD}$. Whether using tocilizumab would confer advantage for reducing $\mathrm{CV}$ risk more than another biologic treatment is not known.

Future directions also include examining the interrelationship between inflammation and traditional CV risk factors, beyond lipids, and how this relationship may differ from the general population. Finally, RA is a human model of inflammation where the levels of inflammation are exaggerated compared to the general population. The higher levels of inflammation serve as a magnifying glass, providing more power to study the pathways and mechanisms of inflammation that impact CVD. As highlighted by the ongoing CIRT study, what we learn from studying RA patients can lead to potential benefits for everyone. 


\section{Acknowledgments}

Dr. Liao is supported by the NIH K08 AR060257, NIH R01 HL127118, and the Harold and Duval Bowen Fund.

\section{SELECTED REFERENCES}

1. Landre-Beauvais AJ. The first description of rheumatoid arthritis. Unabridged text of the doctoral dissertation presented in 1800. Joint, bone, spine : revue du rhumatisme. 2001 Mar; 68(2):130-143.

2. Avina-Zubieta JA, Choi HK, Sadatsafavi M, Etminan M, Esdaile JM, Lacaille D. Risk of cardiovascular mortality in patients with rheumatoid arthritis: a meta-analysis of observational studies. Arthritis and rheumatism. 2008 Dec 15; 59(12):1690-1697. [PubMed: 19035419]

3. Avina-Zubieta JA, Thomas J, Sadatsafavi M, Lehman AJ, Lacaille D. Risk of incident cardiovascular events in patients with rheumatoid arthritis: a meta-analysis of observational studies. Annals of the rheumatic diseases. 2012 Sep; 71(9):1524-1529. [PubMed: 22425941]

4. Solomon DH, Karlson EW, Rimm EB, Cannuscio CC, Mandl LA, Manson JE, et al. Cardiovascular morbidity and mortality in women diagnosed with rheumatoid arthritis. Circulation. 2003 Mar 11; 107(9):1303-1307. [PubMed: 12628952]

5. Mackey RH, Kuller LH, Deane KD, Walitt BT, Chang YF, Holers VM, et al. Rheumatoid Arthritis, Anti-Cyclic Citrullinated Peptide Positivity, and Cardiovascular Disease Risk in the Women's Health Initiative. Arthritis \& rheumatology (Hoboken, NJ. 2015 Sep; 67(9):2311-2322.

6. Gabriel SE, Crowson CS, Kremers HM, Doran MF, Turesson C, O'Fallon WM, et al. Survival in rheumatoid arthritis: a population-based analysis of trends over 40 years. Arthritis and rheumatism. 2003 Jan; 48(1):54-58. [PubMed: 12528103]

7. Gonzalez A, Maradit Kremers H, Crowson CS, Nicola PJ, Davis JM >3rd, Therneau TM, et al. The widening mortality gap between rheumatoid arthritis patients and the general population. Arthritis and rheumatism. 2007 Nov; 56(11):3583-3587. [PubMed: 17968923]

8. An J, Cheetham TC, Reynolds K, Alemao E, Kawabata H, Liao KP, et al. Traditional Cardiovascular Disease Risk Factor Management in Rheumatoid Arthritis Compared to Matched Nonrheumatoid Arthritis in a US Managed Care Setting. Arthritis care \& research. 2016 May; 68(5):629-637. [PubMed: 26414069]

9. Everett BM, Pradhan AD, Solomon DH, Paynter N, Macfadyen J, Zaharris E, et al. Rationale and design of the Cardiovascular Inflammation Reduction Trial: a test of the inflammatory hypothesis of atherothrombosis. American heart journal. 2013 Aug; 166(2):199-207. e15. [PubMed: 23895801]

10. Micha R, Imamura F, Wyler von Ballmoos M, Solomon DH, Hernan MA, Ridker PM, et al. Systematic review and meta-analysis of methotrexate use and risk of cardiovascular disease. The American journal of cardiology. 2011 Nov 1; 108(9):1362-1370. [PubMed: 21855836]

11. D'Agostino RB Sr, Vasan RS, Pencina MJ, Wolf PA, Cobain M, Massaro JM, et al. General cardiovascular risk profile for use in primary care: the Framingham Heart Study. Circulation. 2008 Feb 12; 117(6):743-753. [PubMed: 18212285]

12. Conroy RM, Pyorala K, Fitzgerald AP, Sans S, Menotti A, De Backer G, et al. Estimation of tenyear risk of fatal cardiovascular disease in Europe: the SCORE project. European heart journal. 2003 Jun; 24(11):987-1003. [PubMed: 12788299]

13. Crowson CS, Matteson EL, Roger VL, Therneau TM, Gabriel SE. Usefulness of risk scores to estimate the risk of cardiovascular disease in patients with rheumatoid arthritis. The American journal of cardiology. 2012 Aug 1; 110(3):420-424. [PubMed: 22521305]

14. Goff DC Jr, Lloyd-Jones DM, Bennett G, Coady S, D'Agostino RB, Gibbons R, et al. 2013 ACC/AHA guideline on the assessment of cardiovascular risk: a report of the American College of Cardiology/American Heart Association Task Force on Practice Guidelines. Circulation. 2014 Jun 24; 129(25 Suppl 2):S49-S73. [PubMed: 24222018]

15. Kawai VK, Chung CP, Solus JF, Oeser A, Raggi P, Stein CM. The ability of the 2013 ACC/AHA cardiovascular risk score to identify rheumatoid arthritis patients with high coronary artery calcification scores. Arthritis \& rheumatology. 2015 Feb.

16. Iannaccone CK, Lee YC, Cui J, Frits ML, Glass RJ, Plenge RM, et al. Using genetic and clinical data to understand response to disease-modifying anti-rheumatic drug therapy: data from the 
Brigham and Women's Hospital Rheumatoid Arthritis Sequential Study. Rheumatology. 2011 Jan; 50(1):40-46. [PubMed: 20847201]

17. Ong KL, Allison MA, Cheung BM, Wu BJ, Barter PJ, Rye KA. Trends in C-reactive protein levels in US adults from 1999 to 2010. American journal of epidemiology. 2013 Jun 15; 177(12):14301442. [PubMed: 23669654]

18. Arts EE, Popa C, Den Broeder AA, Semb AG, Toms T, Kitas GD, et al. Performance of four current risk algorithms in predicting cardiovascular events in patients with early rheumatoid arthritis. Annals of the rheumatic diseases. 2013 Apr; 74(4):668-674.

19. Peters MJ, Symmons DP, McCarey D, Dijkmans BA, Nicola P, Kvien TK, et al. EULAR evidencebased recommendations for cardiovascular risk management in patients with rheumatoid arthritis and other forms of inflammatory arthritis. Annals of the rheumatic diseases. 2010 Feb; 69(2):325331. [PubMed: 19773290]

20. van Sijl AM, Peters MJ, Knol DK, de Vet HC, Gonzalez-Gay MA, Smulders YM, et al. Carotid intima media thickness in rheumatoid arthritis as compared to control subjects: a meta-analysis. Seminars in arthritis and rheumatism. 2011 Apr; 40(5):389-397. [PubMed: 20889191]

21. del Rincón IPJF, O'Leary DH, Battafarano DF, Erikson JM, Restrepo JFME, Escalante A. Systemic inflammation and cardiovascular risk factors predict rapid progression of atherosclerosis in rheumatoid arthritis. Annals of the rheumatic diseases. 2015 Jun; 74(6):1118-1123. 2015. [PubMed: 24845391]

22. Gonzalez-Juanatey C, Llorca J, Martin J, Gonzalez-Gay MA. Carotid intima-media thickness predicts the development of cardiovascular events in patients with rheumatoid arthritis. Seminars in arthritis and rheumatism. 2009 Apr; 38(5):366-371. [PubMed: 18336869]

23. Bitton A, Gaziano TA. The Framingham Heart Study's impact on global risk assessment. Progress in cardiovascular diseases. 2010 Jul-Aug;53(1):68-78. [PubMed: 20620429]

24. Arts E. A Transatlantic Cardiovascular Risk Calculator for Rheumatoid Arthritis (ATACC-RA) [abstract]. Annals of the rheumatic diseases. 2014; 73(S2)

25. Solomon DH, Greenberg J, Curtis JR, Liu M, Farkouh ME, Tsao P, et al. Derivation and internal validation of an expanded cardiovascular risk prediction score for rheumatoid arthritis: a Consortium of Rheumatology Researchers of North America Registry Study. Arthritis \& rheumatology. 2015 May; 67(8):1995-2003. [PubMed: 25989470]

26. Goekoop-Ruiterman YP, de Vries-Bouwstra JK, Allaart CF, van Zeben D, Kerstens PJ, Hazes JM, et al. Comparison of treatment strategies in early rheumatoid arthritis: a randomized trial. Annals of internal medicine. 2007 Mar 20; 146(6):406-415. [PubMed: 17371885]

27. Giles JT, Post WS, Blumenthal RS, Polak J, Petri M, Gelber AC, et al. Longitudinal predictors of progression of carotid atherosclerosis in rheumatoid arthritis. Arthritis and rheumatism. 2011 Nov; 63(11):3216-3225. [PubMed: 21965129]

28. del Rincon I, Williams K, Stern MP, Freeman GL, O'Leary DH, Escalante A. Association between carotid atherosclerosis and markers of inflammation in rheumatoid arthritis patients and healthy subjects. Arthritis and rheumatism. 2003 Jul; 48(7):1833-1840. [PubMed: 12847676]

29. Treatments Against RA and Effects on FDG-PET/CT. [cited 2016 3/13/2016] ClinicalTrialsgov [Internet]. 2016. Available from: https://clinicaltrials.gov/ct2/show/NCT02374021

30. Liao KP, Cai T, Gainer VS, Cagan A, Murphy SN, Liu C, et al. Lipid and lipoprotein levels and trends in rheumatoid arthritis compared to the general population. Arthritis care \& research. 2013 Aug 7; 65(12):2046-2050. [PubMed: 23925980]

31. Navarro-Millan I, Charles-Schoeman C, Yang S, Bathon JM, Bridges SL Jr, Chen L, et al. Changes in lipoproteins associated with methotrexate or combination therapy in early rheumatoid arthritis: results from the treatment of early rheumatoid arthritis trial. Arthritis and rheumatism. 2013 Jun; 65(6):1430-1438. [PubMed: 23460074]

32. McInnes IB, Thompson L, Giles JT, Bathon JM, Salmon JE, Beaulieu AD, et al. Effect of interleukin-6 receptor blockade on surrogates of vascular risk in rheumatoid arthritis: MEASURE, a randomised, placebo-controlled study. Annals of the rheumatic diseases. 2013 Dec 24.

33. Singh JA, Beg S, Lopez-Olivo MA. Tocilizumab for rheumatoid arthritis: a Cochrane systematic review. The Journal of rheumatology. 2011 Jan; 38(1):10-20. [PubMed: 20952462] 
34. Kremer JM, Bloom BJ, Breedveld FC, Coombs JH, Fletcher MP, Gruben D, et al. The safety and efficacy of a JAK inhibitor in patients with active rheumatoid arthritis: Results of a double-blind, placebo-controlled phase IIa trial of three dosage levels of CP-690,550 versus placebo. Arthritis and rheumatism. 2009 Jul; 60(7):1895-1905. [PubMed: 19565475]

35. Liao KP, Playford MP, Frits ML, Coblyn JS, Iannaccone CK, Weinblatt ME, et al. The association between reduction in inflammation and changes in lipoprotein levels and HDL cholesterol efflux capacity in rheumatoid arthritis. Journal of the American Heart Association. 2015 Accepted.

36. Charles-Schoeman C, Lee YY, Grijalva V, Amjadi S, FitzGerald J, Ranganath VK, et al. Cholesterol efflux by high density lipoproteins is impaired in patients with active rheumatoid arthritis. Annals of the rheumatic diseases. 2012 Jul; 71(7):1157-1162. [PubMed: 22267330]

37. Libby P. Role of inflammation in atherosclerosis associated with rheumatoid arthritis. The American journal of medicine. 2008 Oct; 121(10 Suppl 1):S21-S31. [PubMed: 18926166]

38. Hingorani AD, Casas JP. The interleukin-6 receptor as a target for prevention of coronary heart disease: a mendelian randomisation analysis. Lancet. 2012 Mar 31; 379(9822):1214-1224. [PubMed: 22421340]

39. Hospital, OU. Effect of the Interleukin-6 Receptor Antagonist Tocilizumab in Non-ST Elevation Myocardial Infarction. 2014. NCT01491074:[Available from: [cited 2016]

40. Newby AC. Metalloproteinases and vulnerable atherosclerotic plaques. Trends in cardiovascular medicine. 2007 Nov; 17(8):253-258. [PubMed: 18021934]

41. Fiedorczyk M, Klimiuk PA, Sierakowski S, Gindzienska-Sieskiewicz E, Chwiecko J. Serum matrix metalloproteinases and tissue inhibitors of metalloproteinases in patients with early rheumatoid arthritis. The Journal of rheumatology. 2006 Aug; 33(8):1523-1529. [PubMed: 16881109]

42. Tchetverikov I, Lard LR, DeGroot J, Verzij1 N, TeKoppele JM, Breedveld FC, et al. Matrix metalloproteinases-3, $-8,-9$ as markers of disease activity and joint damage progression in early rheumatoid arthritis. Annals of the rheumatic diseases. 2003 Nov; 62(11):1094-1099. [PubMed: 14583574]

43. Okada Y, Wu D, Trynka G, Raj T, Terao C, Ikari K, et al. Genetics of rheumatoid arthritis contributes to biology and drug discovery. Nature. 2014 Feb 20; 506(7488):376-381. [PubMed: 24390342]

44. Li G, Diogo D, Wu D, Spoonamore J, Dancik V, Franke L, et al. Human genetics in rheumatoid arthritis guides a high-throughput drug screen of the CD40 signaling pathway. PLoS genetics. 2013 May.9(5):e1003487. [PubMed: 23696745]

45. MacDonald KP, Nishioka Y, Lipsky PE, Thomas R. Functional CD40 ligand is expressed by T cells in rheumatoid arthritis. The Journal of clinical investigation. 1997 Nov 1; 100(9):2404-2414. [PubMed: 9410920]

46. Berner B, Wolf G, Hummel KM, Muller GA, Reuss-Borst MA. Increased expression of CD40 ligand (CD154) on CD4+ T cells as a marker of disease activity in rheumatoid arthritis. Annals of the rheumatic diseases. 2000 Mar; 59(3):190-195. [PubMed: 10700427]

47. Schonbeck U, Varo N, Libby P, Buring J, Ridker PM. Soluble CD40L and cardiovascular risk in women. Circulation. 2001 Nov 6; 104(19):2266-2268. [PubMed: 11696462]

48. Vasan RS. Biomarkers of cardiovascular disease: molecular basis and practical considerations. Circulation. 2006 May 16; 113(19):2335-2362. [PubMed: 16702488]

49. Aubry MC, Maradit-Kremers H, Reinalda MS, Crowson CS, Edwards WD, Gabriel SE. Differences in atherosclerotic coronary heart disease between subjects with and without rheumatoid arthritis. The Journal of rheumatology. 2007 May; 34(5):937-942. [PubMed: 17361987]

50. Foster W, Carruthers D, Lip GY, Blann AD. Inflammation and microvascular and macrovascular endothelial dysfunction in rheumatoid arthritis: effect of treatment. The Journal of rheumatology. 2010 Apr; 37(4):711-716. [PubMed: 20156948]

51. Ciftci O, Yilmaz S, Topcu S, Caliskan M, Gullu H, Erdogan D, et al. Impaired coronary microvascular function and increased intima-media thickness in rheumatoid arthritis. Atherosclerosis. 2008 Jun; 198(2):332-337. [PubMed: 18164712] 
52. Turiel M, Atzeni F, Tomasoni L, de Portu S, Delfino L, Bodini BD, et al. Non-invasive assessment of coronary flow reserve and ADMA levels: a case-control study of early rheumatoid arthritis patients. Rheumatology. 2009 Jul; 48(7):834-839. [PubMed: 19465588]

53. Avouac J, Meune C, Chenevier-Gobeaux C, Dieude P, Borderie D, Lefevre G, et al. Inflammation and disease activity are associated with high circulating cardiac markers in rheumatoid arthritis independently of traditional cardiovascular risk factors. The Journal of rheumatology. 2014 Feb; 41(2):248-255. [PubMed: 24334650]

54. Barber CE, Smith A, Esdaile JM, Barnabe C, Martin LO, Faris P, et al. Best practices for cardiovascular disease prevention in rheumatoid arthritis: A systematic review of guideline recommendations and quality indicators. Arthritis care \& research. 2014 Jul 29.

55. Kitas GD, Nightingale P, Armitage J, Sattar N, Belch J, Symmons DPM, et al. Trial of Atorvastatin for the Primary Prevention of Cardiovascular Events in Patients with Rheumatoid Arthritis [abstract]. Arthritis \& Rheumatism. 2015; 67(S10)

56. Ljung L, Rantapaa-Dahlqvist S, Jacobsson LT, Askling J. Response to biological treatment and subsequent risk of coronary events in rheumatoid arthritis. Annals of the rheumatic diseases. 2016 Mar 16.

57. Jacobson TA, Maki KC, Orringer CE, Jones PH, Kris-Etherton P, Sikand G, et al. National Lipid Association Recommendations for Patient-Centered Management of Dyslipidemia: Part 2. Journal of clinical lipidology. 2015 Nov-Dec;9(6 Suppl):S1-S122. e1. 


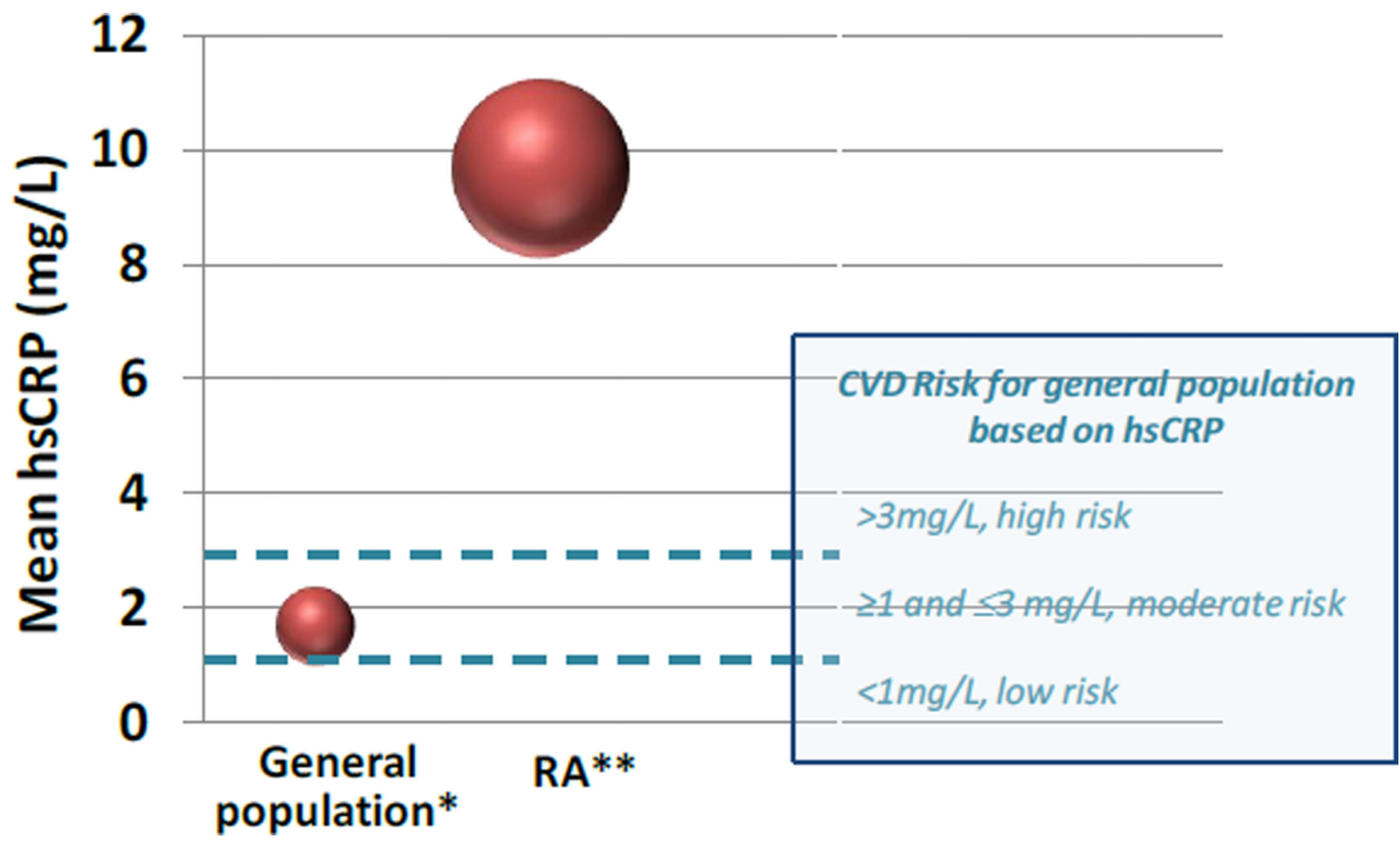

Figure 1.

The mean hsCRP from a general population cohort*, hsCRP cut-off values for CV risk estimation in the general population, compared to the mean hsCRP from a typical RA cohort**. [*National Health and Nutrition Examination Survey (NHANES), **Brigham Rheumatoid Arthritis Sequential Study (BRASS)] 